\title{
Observation of microstructure of silty sand obtained from gel- push sampler and reconstituted sample
}

\author{
Muhamad Yusa ${ }^{1, *}$, E.T Bowman ${ }^{2}$, and Misko Cubrinovski \\ ${ }^{1}$ Civil Engineering Department, University of Riau, Indonesia \\ ${ }^{2}$ Civil and Structural Engineering, University of Sheffield, United Kingdom \\ ${ }^{3}$ Civil and Natural Resources Engineering, University of Canterbury, New Zealand
}

\begin{abstract}
Observation of microstructure study of natural sand i.e. clean sand with fines (particles adjudged to be smaller than $75 \mu \mathrm{m}$ ) content $<5 \%$ (Gel Push A) and silty sand with $35 \%$ fine content (Gel Push B) obtained by gel-push sampling was described. In addition, some observations from reconstituted samples prepared by dry pluviation and moist tamping were presented. Microstructures were investigated statistically by measuring particle orientation. It was evidence that natural sand (either gel push A and B) have a preferred orientation i.e. horizontally oriented. Similar particle orientation trend were observed by dry pluviated sample. Undisturbed and dry pluviated samples shows that they are anisotropic in terms of particles orientation. Moist tamped sample on the other hand, results in fairly random orientation with a slight bias towards vertical, thus does not replicate natural sand fabric.
\end{abstract}

\section{Introduction}

Mechanical behaviour of granular material is well known to be dependend on its microstructure.However, obtaining natural undisturbed granular soils is difficult, due to its non-cohesive nature, which results in limited studies on it. Furthermore, most granular materials occurring in nature are composed of a broad range of particle sizes [1], whereas the few studies on soil microstructure have focused on clean, usually uniform soils, such as Bowman \& Soga[2]. Indeed, some insight was obtained from numerical model using discrete element method

This research describes observations of the microstructure of silty sands in an 'undisturbed state'. The 'undisturbed samples' were obtained via gel push sampler. In addition this study also investigates microstructural of reconstituted samples prepared by dry funnel pluviation [3] and moist tamping[4].

\section{Gel Push Sampling}

Gel push sampling was first developed in 1999 in Japan to obtain samples of sandy, gravelly soil and fractured rock. The method then progressively has been developed and modified by Kiso-Jiban Consultants and the Taiwan Construction Research Institute under the guidance of Prof. Ishihara [5].
The method utilizes high density polymer solution at very low velocity without circulation (preventing loss of fine particles) to reduce the friction between the cut sample and the sample tube. Before sampling, the space for containing the sample is filled with high density polymer solution. When the sample comes into the space, the high density polymer solution is pushed out and coats the Gel Push and minimizes the sample disturbance caused by the friction and the sample tube. Figure 1 illustrates the sampling process. The polymer coated on the sample is gelated and semi hardened the surface to protect the sample. The method was brought to New Zealand as part of University of Canterbury Research Project on liquefaction assessment of Christchurch $[6,7]$.

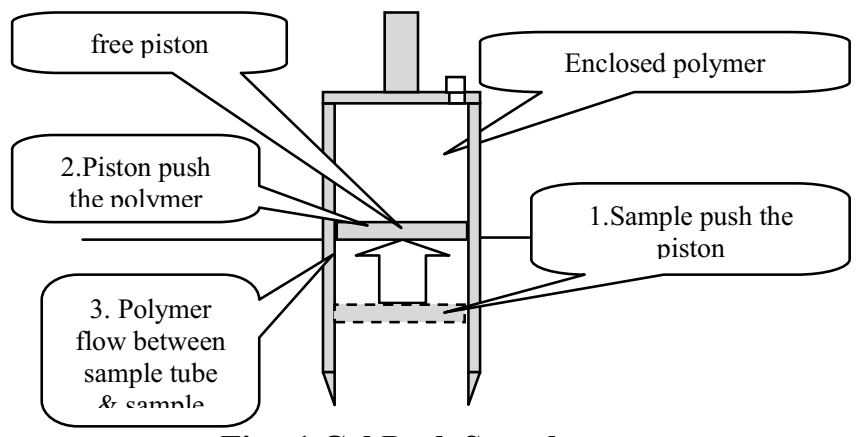

Fig. 1 Gel Push Sampler

\section{Microstructure Measurement}

In general there are two measurements used to quantify the microstructure changes i.e. particle orientation and 
distribution of spatial distance between particles. However due to limited space only the first parts is discussed herein. In addition, it is realized that two dimensional image analysis results in loss information of the pore structure and other attributes of three dimensional microstructure. However, this study is concentrated on retrieving some basic trends of microstructure of 'undisturbed' and reconstituted silty sands thus two dimensional microstructure measurements was deemed adequate.

The orientation of a non-spherical particle can be represented by the orientation of the long axis of the particle to a reference axis. The true three dimensional long axis of the particle is difficult to determine. Thus in this study particle orientation is defined by the angle of the apparent long axis of the projected particle in two dimensions (vertical plane in this study). The measure is represented by a rose diagram. Statistical parameters are then determined to summarize the distribution of particle orientation using Fisher distribution analysis [8].

Mean angle $\left(\alpha_{\mathrm{m}}\right)$ can be determined as follows:

$$
\alpha_{m}=\frac{1}{2} \tan ^{-1}\left(\left\{\sum_{i=1}^{N}\left[l_{i} \sin \left(2 \alpha_{i}\right]\right\} /\left\{\sum_{i=1}^{N}\left[l_{i} \cos \left(2 \alpha_{i}\right]\right\}\right)\right.\right.
$$

where $l_{i}$ is the length of long axes of the particle, $\mathrm{N}$ is the number of measurements, $\alpha$ is the angle between the unit vector and the true direction. In addition, $\kappa$, was used to indicate degree of concentration and can be estimated from the equation below [9]

where

$$
x=\frac{N-1}{N-R}
$$

$$
R^{2}-\sqrt{\left\{\sum_{2=1}^{N}\left[l_{i}, \sin (2 \alpha]\right)^{2}+\left\{\sum_{i=1}^{N}\left[l_{i}, \cos (2 \alpha]\right\}^{2}\right.\right.}
$$

An increase in $\kappa$ suggests a relative increase of isotropy in term of particle orientation. Rose diagrams and Fischer statistical analysis were drawn and calculated by the aid of Geo-Orient ver. 9.5.0 developed by Dr. Rod Holcombe [10].

\section{Experimental Methodology}

\subsection{Material}

Natural sands used in this study were ejected material from two sites around Christchurch City Centre i.e. Kilmore Street (Gel Push A) and Madras Street (Gel Push B) following the Canterbury Earthquake [11]. The particle size distributions (PSD) are shown by Figure 2. Gel Push A was relatively clean sand with $4 \%$ fine particles (smaller than 75 micron), whereas Gel Push B was silty sand with $35 \%$ fines. The mean diameter of Gel Push A and B are 235 micron and 95 micron respectively.. Lab $\mathrm{C}$ is non-plastic silty sand with mean diameter of 150 micron and $15 \%$ fines. Lab C was prepared in order to make a comparison between the microstructure of natural undisturbed soil and reconstituted soil. Lab $\mathrm{C}$ was reconstituted by dry funnel pluviation (Lab C-DD) and mois tamping (Lab C-MT) to a relative density of $40 \%$ (loose).

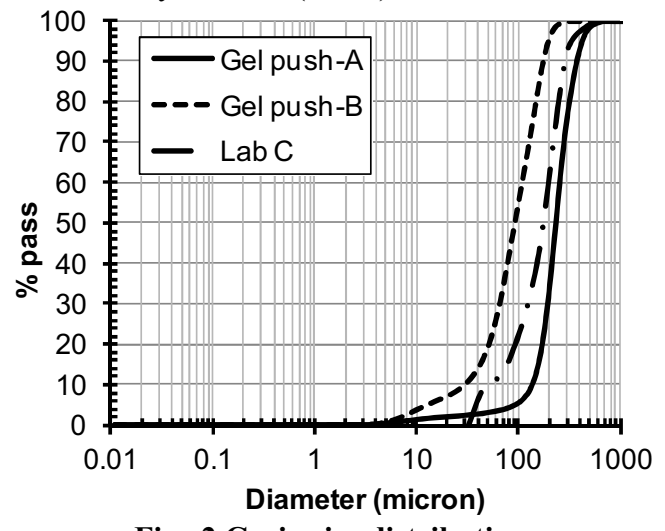

Fig. 2 Grain size distributions

\subsection{Experimental methodology}

The methodology used in this study is briefly described here. Detail of the methodology was explained in another paper [12].

\subsubsection{Sample preservation}

Considering that the natural soils used in this study involve irregular shape, wide particle distribution and fine particles, it was decided to adopt a direct method of preservation i.e. injection a low viscosity epoxy resin [13].

\subsubsection{Sample preparation and loading}

Gel Push-A and B samples were loaded one dimensionally $\left(\mathrm{K}_{0}\right.$ condition) to $80 \mathrm{kPa}$ and $50 \mathrm{kPa}$ vertical stress, respectively, which correspond to estimated field stress. For Lab $\mathrm{C}$, the samples were loaded under a vertical stress of $125 \mathrm{kPa}$, which was in accordance to the stress during triaxial $\mathrm{K}_{0}$ consolidation with $60 \mathrm{kPa}$ confining pressure.

\subsubsection{Capturing image}

Images were captured (at $45 \mathrm{x}$ magnification) using a scanning electron microscope via back scattered detection (Llyod, 1987). Material with higher atomic weight appears brighter compared to those with lower ones. This gives clear contrast between the grains and the epoxy filled voids.

\subsubsection{Image processing}

Captured images were processed and analyzed using image analysis software ImagePro Plus v.7.0. Steps involved in this process include contrast enhancement, correction for noise and thresholding. The resulting image is displayed as a binary image using black and white colors to distinguish foreground and background 
regions. Subsequent steps were filling the grain holes and watershed splitting to separate the grains.

\section{Results}

Examples of captured and processed images from gel push A, gel push B, lab C-DD and lab C-MT are presented in Figure 3 (a) to Figure 3(d) respectively. It is interesting to be noted from the figures, particularly for gel $\mathrm{B}$ and lab C, visible band of fines particles. For gel push $B$ the silt band is visible running from the left edge to the top. This suggests that segregation between fines and larger particle is something natural in the field. Reconstituted lab C-DD shows band of silt running from the bottom to the right edge which indicates that segregation is encountered in dry pluviated sample. While lab C-MT shows no clear segregation. The statistical analysis involves approximately 1800, 18000 and 9000 particles for Gel Push A, gel Push B and lab C, respectively.

One factor that influences the final orientation of particles settling under gravity is the particle aspect ratio [14] .The particle aspect ratio exhibits quantitative influence on particle orientation, contact normal and sliding contact normal[15-17]. Figure 4 shows normalized frequency (divided frequency in each bin by total number of particles) distribution histograms of aspect ratio are shown by The calculations did not include particles touching the perimeter of the image because that would introduce $\mathrm{s}$ into the results. It can be seen that most particles (approximately 70\%) for both Gel Push A and B have aspect ratio between 1.5 and 2, showing that many particles are elongated. A similar aspect ratio distribution was found for Lab C.

Table 1 shows result of circular statistical analysis. Separate analysis for 'sand size' particles and 'fines'sized particles were also performed in order to see anisotropy between large and small grains. It is realized that it is difficult to determine which particles truly are fines (less than 75 micron in diameter in a sieve analysis) due to the $2 \mathrm{D}$ slice through each of the particles, which may not occur diametrically. Effort was trialled to differentiate fines from sand (for Lab C) based on the material composition utilizing tools on SEM via back scattered detector. However, the fines $(99.8 \%$ silica dioxide) and some of the sand were found to have a very similar atomic weight. Thus it is not possible to differentiate whether fines sized particles were truly fines or corners of sand particles. Regardless it can be determined that particles having a feret minimum equal to or larger than 75 micron are sand. Feret minimum is the smallest the distance between two parallel tangents of the particle at an arbitrary angle, and is often used as the diameter equivalent to a sieve analysis [18]. In this study, the rest of the particles are assumed to be fines. This results in higher fines percentages than those from particle size distribution e.g. $5.2 \%$ (gel push-A) and $26 \%$ (lab C) compared to $4 \%$, and $15 \%$ of those from grain size distribution.

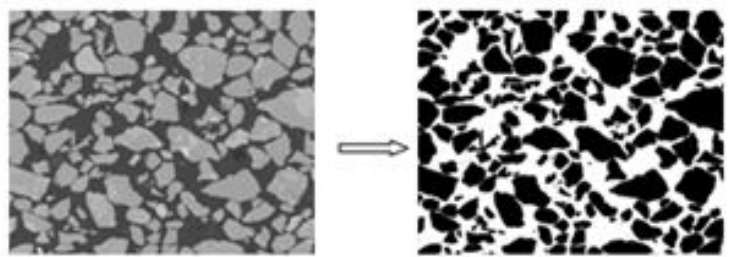

(a)
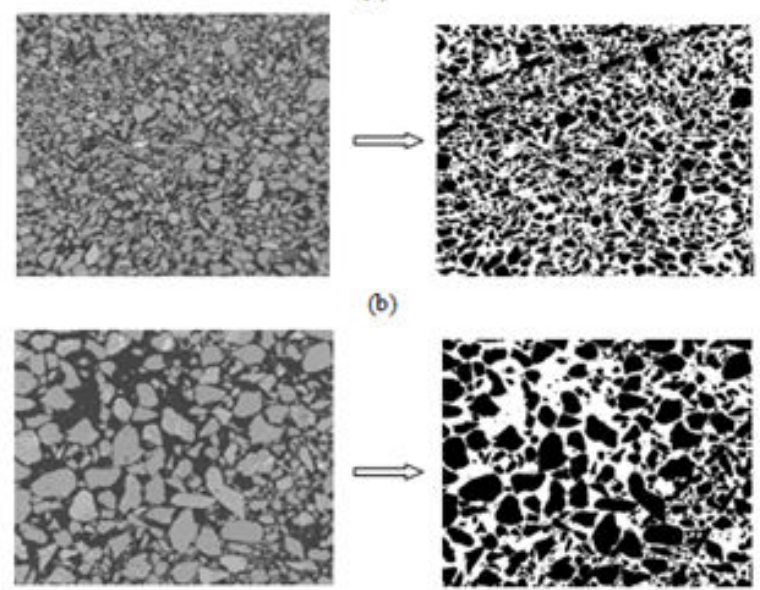

(b)

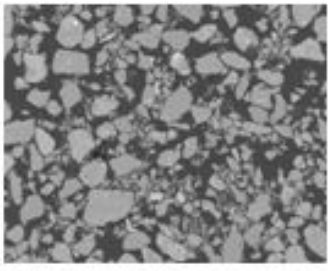

(c)
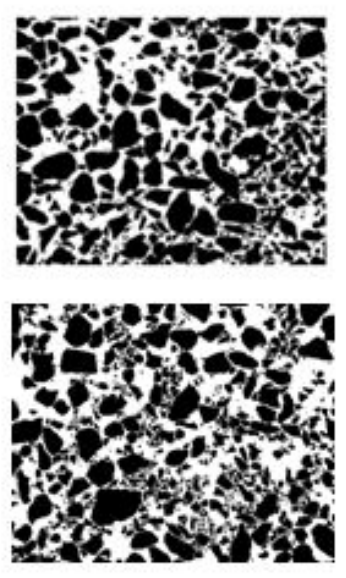

(d)

Fig. 3 Example of captured and processed images

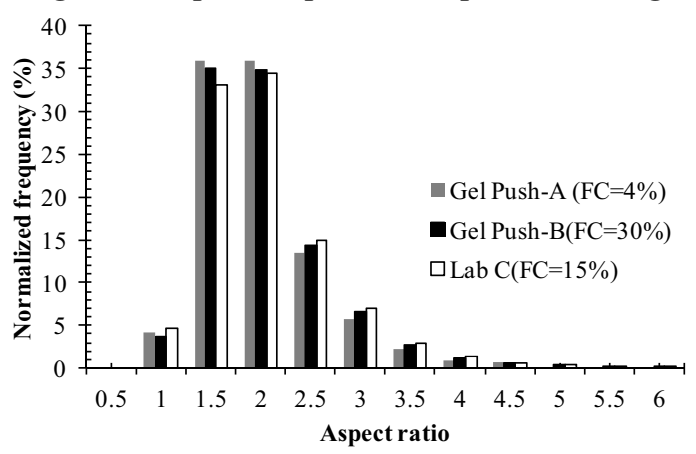

Fig. 4 Frequency distribution of aspect ratio

It can be seen from Table 1, Figure 5 and Figure 6 that the fabric of natural undisturbed sand (Gel Push A and B) has a preferred apparent orientation to the horizontal with mean angles of $2.2^{\circ}$ and $0.9^{\circ}$ to the horizontal axis. A similar trend was found for Lab C-DD, with a slightly larger mean angle i.e. $3.5^{\circ}$ but still horizontally oriented. In addition, the Table also reveals that generally both sand size particles and fines from gel push and dry sample tend to be oriented in the same direction. Moreover, both gel push and reconstituted samples, in general, reveal that fines are less orientated than sand particles, as indicated by smaller $\kappa$ values. On the other hand, figure 6 shows that moist tamped sample is more isotropic than dry pluviated samples. This is in 
accordance with $\kappa$ values of moist tamped samples which is less than those of dry pluviated samples, indicating higher isotropy of moist tamped samples. Similar to gel push and dry pluviated sample, sand particles are more orientated than 'fines'. Furthermore, 'fines' of moist tamped samples are much less orientated than those of gel push and dry pluviated sample as suggested by lower values of $\kappa$ values.

Table 1 Fischer statistical analysis results

\begin{tabular}{|c|c|c|}
\hline Sample & $\alpha_{\mathrm{m}}\left({ }^{\circ}\right)^{*}$ & $\kappa$ \\
\hline Gel Push A - All & $87.8 \pm 1.2$ & 0.53 \\
\hline Sand size & $88.9 \pm 0.9$ & 0.60 \\
\hline 'Fines size' & $81.9 \pm 3.0$ & 0.33 \\
\hline Gel Push B - All & $89.1 \pm 0.7$ & 0.52 \\
\hline Sand size & $87.3 \pm 0.9$ & 0.80 \\
\hline 'Fines size' & $89.1 \pm 0.6$ & 0.51 \\
\hline Lab C-DD - All & $86.5 \pm 1.1$ & 0.42 \\
\hline Sand size & $86.5 \pm 0.8$ & 0.65 \\
\hline 'Fines size' & $87.1 \pm 1.3$ & 0.29 \\
\hline Lab C-MT - All & $177.9 \pm 2.3$ & 0.14 \\
\hline Sand size & $0.1 \pm 1.8$ & 0.30 \\
\hline 'Fines size' & $169.5 \pm 8.9$ & 0.05 \\
\hline
\end{tabular}

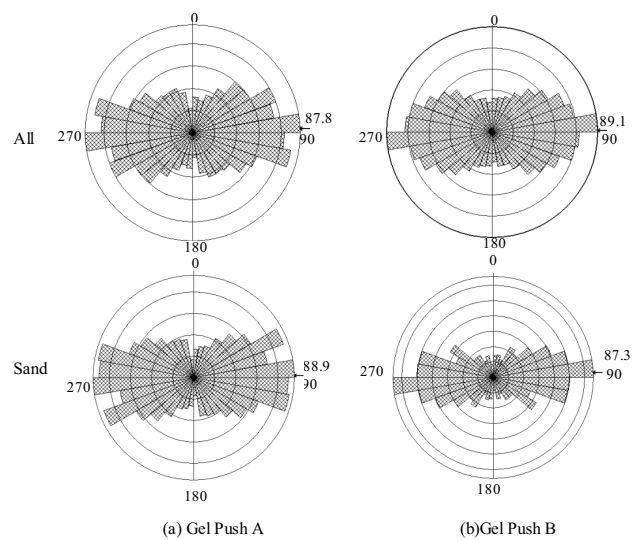

Fig. 5 Rose diagram based on gel-push sample

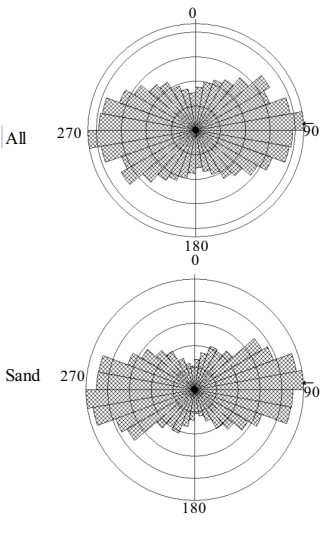

(a)

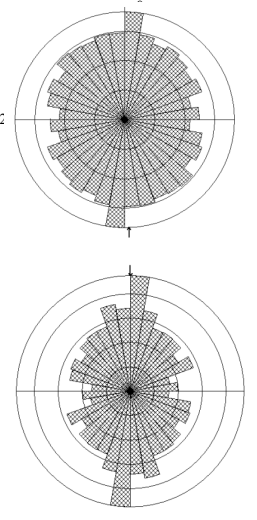

(b)
Fig. 6 Rose diagram based on reconstituted sample (a) dry pluviation (b) moist tamping

\section{Conclusions}

Method and observation of microstructure of sand containing fines from gel push samples and reconstituted sample have been described. Based on the circular statistical analysis, microstructure of natural sand and dry pluviated samples have similar preferred orientation which is horizontally oriented in this study. In addition both gel push sample sand and dry pluviated samples tend to be anisotropic in term of particle orientation. In contrast, moist tamping sample tend to be isotropic.This indicates dry funnel pluviation could be used to mimic microstructure of natural sand.

\section{References}

1. Mitchell, J.K. and K. Soga, Fundamentals of soil behavior. 3rd ed. (2005), New York: Wiley.

2. Bowman, E.T. and K. Soga, SOILS FOUND, (2003). 43(4): p. 107-117.

3. Ishihara, K., GEOTECHNIQUE, (1993). 63: p. $351-415$.

4. Ladd, R., GEOTECH TEST J, (1978). 1(1): p. 1623.

5. Huang, A.B., et al. 3rd International Conference on Site Characterization. (2008). Taipei: Taylor \&Francis.

6. Taylor, M.L., M. Cubrinovski, and I. Haycock. (2012). New Zealand Society of Earthquake Engineering:2012 Annual Technical Conference.

7. Stringer, M.E., M. Cubrinovski, and I. Haycock. ISC 5. (2016). Gold Coast Australia.

8. Fisher, N.I., Statistical Analysis of Circular Data. (1993): Cambridge University Press.

9. Butler, R.F., Magnetic Domains to Geologic Terranes., 1992.

10. Holcombe, R. Structural Geology - Mapping/GIS Software. n.d. [cited 20133 January]; Available from:

http://www.holcombe.net.au/software/rodh_softwar e georient.htm.

11. Cubrinovski, M. 7th International Conference on Case Histories in Geotechnical Engineering. (2013). Chicago, Illnois-USA.

12. Yusa, M. and E.T. Bowman. Powder and Grain 2013. (2013). Sydney.

13. Palmer, S.N. and M.E. Barton, J. SEDIMENT RES, (1986). 56: p. 556-557.

14. Willmarth, W.W., N.E. Hawk, and R.L. Harvey, The Physic of Fluid, (1964). 7(2).

15. Jiang, M.J., J.D. Liu, and M. Arroyo, International Journal for Numerical and Analytical Methods in Geomechanics, (2016). 40(18): p. 2468-2488.

16. Jiang, M.J., T. Li, and Z.F. Shen, Granular Matter, (2016). 18(3): p. 1-15.

17. Jiang, M.J., T. Li, and Z.F. Shen, Granular Matter, (2016). 18(3): p. 1-14.

18. Sympatech GmBH. 2013 [cited 2013 February 12]; Available from: http://www.sympatec.com/EN/Science/Characteris ation/05 ParticleShape.html. 